\title{
Hubungan Kekuatan Otot Lengan Dan Panjang Lengan Dengan Hasil Servis Atas Bola Voli
}

\author{
Agus Dwi Kuncoro 1 \\ Email : $\underline{\text { dwikun91@gmail.com }}{ }^{1}$ \\ 1 Program Studi Pendidikan Olahraga Fakultas Keguruan Ilmu Pendidikan Universitas \\ Muhammadiyah Surakarta
}

\begin{abstract}
Abstrak
Tujuan penelitian adalah untuk mengetahui hubungan kekuatan otot lengan dan panjang lengan dengan hasil servis atas pada siswa ekstrakulikuler bola voli SMP 1 Kertek. Desain penelitian menggunakan metode deskriptif kuantitatif dengan jenis penelitiannya termasuk dalam jenis penelitian korelasional. Sampel yang digunakan adalah siswa yang mengikuti ekstrakulikuler berjumlah 16 orang. Tes dan pengukuran adalah teknik yang digunakan dalam pengambilan data. Analisis data menggunakan analisis korelasi dengan menggunkan bantuan aplikasi SPSS 20. Hasil penelitian adalah sebagai berikut ini. Pertama, terdapat adanya hubungan antara kekuatan otot lengan dengan hasil servis atas yang di peroleh rhitung sebesar 0,769 dan rtabel $(16 ; 0,05)$ sebesar 0,497 maka dengan melihat dari tabel interpretasi koefisian korelasi tingkat hubungannya berada pada level tinggi. Kedua, terdapat adanya hubungan antara panjang lengan dengan hasil servis atas yang di peroleh rhitung sebesar 0,548 dan rtabel $(16 ; 0,05)$ sebesar 0,497 maka dengan melihat dari tabel interpretasi koefisian korelasi tingkat hubungannya berada pada level sedang. Ketiga, terdapat adanya hubungan kekuatan otot lengan dan panjang lengan dengan hasil servis atas bola voli yang di peroleh rhitung sebesar 0,858 dan rtabel $(16 ; 0,05)$ sebesar 0,497 maka dengan melihat dari tabel interpretasi koefisian korelasi tingkat hubungannya berada pada level sangat tinggi.
\end{abstract}

Kata Kunci: kekuatan otot lengan; panjang lengan.

\begin{abstract}
The purpose of the study was to determine the relationship between arm muscle strength and arm length with the results of the upper serve on volleyball extracurricular students of SMP 1 Kertek. The research design uses descriptive quantitative methods with the type of research included in the type of correlational research. The sample used was 16 students who took extracurricular activities. Data collection techniques are tests and measurements. Data analysis using correlation analysis using SPSS 20 application assistance. The results of the study are as follows. First, there is a relationship between arm muscle strength and the results of the upper service obtained by rcount of 0.769 and rtable $(16 ; 0.05)$ of 0.497 , so by looking at the interpretation table of the correlation coefficient, the level of the relationship is at a high level. Second, there is a relationship between the length of the arm and the results of the upper service which is obtained rcount of 0.548 and rtable (16 ; 0.05) of 0.497, so by looking at the interpretation table of the correlation coefficient, the level of the relationship is at a medium level. Third, there is a relationship between arm muscle strength and arm length with the results of serving on volleyball which is obtained rcount of 0.858 and rtable (16 ; 0.05) of 0.497, , so by looking at the interpretation table of the correlation coefficient, the level of the relationship is at a very high level
\end{abstract}

Keywords: arm muscle strength; sleeve length 


\section{A. Pendahuluan}

Pendidikan yang melibatkan aktivitas fisik dimana hal tersebut digunakan dalam memproleh kemampuan dan keterampilan jasmani olahraga merupakan arti dari Pendidikan Jasmani. Orang dapat mempelajari hal-hal yang berkaitan dengan afektif, kognitif dan psikomotor melalui pendidikan jasmani. Pendidikan jasmani adalah suatu aktivitas jasmani baik permainan maupun cabang olahraga yang bertujuan untuk memperoleh pendidikan. Akan tetapi seiring berkembangnya ilmu teknologi yang semakin canggih, menyebabkan aktivitas olahraga manusia mulai terhambat. Tidak sedikit orang yang hanya duduk diam dirumah dengan bermain game hingga berjam-jam lamanya. Peserta didik dapat akan mendapatkan pengalaman melalui pembelajaran pendidikan jasmani yang memiliki keterkaitan dengan kepribadian yang nyaman, kreatif dan inovatif, keterampilan mobilitas, kebugaran fisik, gaya hidup sehat, dan pemahan tentang gerakan manusia, membentuk kepribadian yang lebih positif. (Samsudin, 2011). Bahkan sekarang ini siswa lebih memilih malakukan kegiatan yang kurang bermanfaat seperti bermain smartphone dan playstation dibandingkan melakukan aktivitas fisik seperti olahraga. Hal tersebut tentu menjadi sebuah permasalahan bagi guru, khususnya guru olahraga.

Dalam rangka penanganan masalah yang ada maka, penyelengaraan kegiatan ekstrakulikuler disekolah sangat tepat dilakukan. Sehingga ketika jam pembelajaran telah usai siswa memiliki kegiatan yang lebih bermanfaat dibandingkan bermain gadget. Berdasarkan Peraturan (Permendiknas No 22 Tahun 2006) kegiatan ekstrakulikuler dan bimbingan konseling untuk mendukung d pengembangan siswa yang disesuaikan dengan kebutuhan, potensi, bakat, dan minatnya, mereka melalui kegiatan yang secara khusus dilaksanakan oleh guru dan/atau staf sekolah atau madrasah yang berkualitas dan berwewenang. Ekstrakulikuler merupakan alah satu kegiatan luar kelas yang dibimbing oleh pendidik yang memiliki kewenangan guna membantu siswa dalam mengambangkan minat, bakat dan potensi yang kedepannya dapat berfungi untuk peningkatan kemampuan dan lebih mengembangkan rasa tanggung jawab sosial peserta didik. Dengan diadakannya aktivitas ekstrakulikuler dapat menghilangkan stress karena menampung banyak materi di dalam kelas sehingga memberikan suasana rileks, nyaman, menyenangkan, dan menggembirakan. Sekolah memfasilitasi kegiatan ekstrakulikuler baik secara akademik ataupun non akademik. Salah satu dari kegiatan ekstrakulikuler yang disajikan yaitu cabang olahraga bola voli.

Cabang olahraga yang dimainkan oleh dua tim yang berhadapan dimana setiap tim terdiri dari enam pemain merupakan definisi dari permainan bola voli. Dimana tujuan dari permainannya adalah untuk menjatuhkan bola kedaerah lawan dengan cara melewatkan bola melalui atas net dan pantulan bola yang sah atau sesuai dengan peraturan. Adapun dalam permainan bola voli terdapat teknik dasar yang wajib untuk dikuasi adalah teknik service, teknik passing, spike/smash, dan teknik blocking. Menurut (Nurhasan, 2000), teknik dasar merupakan suatu proses memunculkan aktivitas fisik yang digambarkan sebagai gerakan yang bertujuan untuk mencapai sesuatu secara efektif dan efisien. Salah satu teknik dasar bola voli yang penting dan wajib dikuasai adalah teknik passing. Passing sendiri merupakan teknik mengumpang bola kepada kawan. Teknik passing sendiri dibagi menjadi dua jenis, yaitu passing bawah dan passing atas. Menurut (Sistiasih et al., 2019) passing bawah adalah teknik yang digunakan untuk menyusun pola serangan ke tim lawan dan merupakan dasar pola bertahan. Sedangkan passing atas merupakan teknik yang dilakukan dengan perkenaan ujung jari tengah. Teknik service adalah teknik awal dalam permainan bola voli dimana teknik tersebut juga bisa menjadi serangan pertama ke tim lawan. Teknik smash merupakan teknik serangan yang sering digunakan untuk memperoleh poin, gerakan bola yang keras dan 
menukik tajam menjadi serangan yang mematikan (Sistiasih et al., 2019). Teknik block merupakan pertahanan pertama dalam menghadapi serangan dari lawan.

Unsur- unsur yang diperlukan oleh pemain bola voli adalah kelincahan (agility), keseimbangan (balance), kekuatan (strength), koordinasi (coordination), daya tahan otot (endurance), kelentukan (flexibiliy), serta kecepatan mobilitas reaksi (speed). Mengembangkan kekuatan seorang pemain bola voli membutuhkan perhatian yang sangat mendasar selama pelatihan, karena hal tersebut digunakan untuk pengembangan teknik dan fisik. Dari macam-macam teknik dasar diatas, dalam penelitiannya fokus penulis adalah pada keterampilan teknik dasar service. Ada dua jenis service yang ada dalam permainan bola voli, yaitu yang sering disebut dengan service bawah dan service atas. Sebagian orang memandang service atas adalah teknik dasar service yang sulit dikuasai. Oleh sebab itu hanya pemain yang sudah menguasai teknik tersebut yang sering melakukan service atas. Otot lengan dan panjang lengan merupakan anggota tubuh yang terlibat ketika sedang melakukan service atas, hal tersebut yang melandasi penulis melakukan pengamatan. Oleh karena itu, kekuatan otot lengan merupakan kondisi fisik yang fisiologis dimana sangat diperlukan untuk menghasilkan pukulan service atas yang baik (Effendi, 2015).

Kemampuan seseorang menerima beban maksimal menggunakan otot merupakan definisi komponen kondisi fisik yaitu kekuatan. (Ahmadi, 2007). Sebagai daya penggerak unsur yang sangat penting untuk melakukan kegiatan olahraga adalah kekuatan. Kekuatan otot yang maksimal dapat menunjang dalam peningkatan kemampuan kerja seseorang. Kekuatan otot lengan adalah kemampuan otot lengan untuk mengembangkan kekuatan maksimum dengan memaksimalkan kontraksi untuk mengatasi beban dan hambatan (Alimin, 2019). Otot - otot pada tubuh manusia memiliki fungsinya masing-masing dan bekerja sesuai fungsinya. Seperti halnya otot lengan yang sangat berpengaruh dan berperan penting dalam melakukan service bola voli. Sebuah tangan dengan tuas panjang dipengaruhi oleh kecepatan gerakan dan sebanding dengan besarnya radius yaitu panjang lengan. Jadi semakin besar radiusnya, semakin besar pula kecepatannya. Lengan panjang berkontribusi dalam pelaksanaan pukulan service dengan (Istyadi, 2007). Dari pengamatan peneliti pada siswa elstrakuler bola voli SMP 1 Kertek melihat hanya sebagian siswa yang dapat melakukan servis atas dengan baik. Adapun Faktor yang mungkin mempengaruhi servis tersebut yaitu postur tubuh siswa dan kekuatan dari siswa tersebut. Hal ini yang membuat prestasi dalam permainan bola voli SMP 1 Kertek sulit untuk ditingkatkan. Hal tersebut yang menjadi dasar bagi peneliti untuk melakukan penelitian yang berjudul "Hubungan Kekuatan Otot Lengan dan Panjang Lengan Dengan Hasil Servis Atas Pada Siswa Ekstrakulikuler Bola voli Smp 1 Kertek".

\section{B. Metode}

Metode penelitian merupakan faktor penting sangat mempengaruhi hasil penelitian . Dalam kegiatan penelitian, suatu langkah atau prosedur operasional harus di setting sedemikan rupa sehingga dalam pelaksanaannya memerlukan metode tertentu. Penelitian yang berbotot adalah penelitian yang bertanggung jawab atas metode penelitiannya. Penelitian ini menggunkan metode deskriptif kuantitatif dan jenis penelitiannya termasuk dalam kategori penelitian korelasi. Jenis penelitian korelasional ini digunakan untuk melihat hubungan antara variabel bebas dengan variabel terikat. Populasi pada penelitian ini berjumlah 16 siswa dari SMP 1 Kertek Kabupaten Wonosobo yang mengikuti ekstrakulikuler bola voli. Pengambilan sample dengan teknik purposive sampling yang digunakan dalam penelitian ini. Purposive sampling adalah metode pengambilan sample dengan menetapkan kriteria-kriteria tertentu (Sugiyono, 2015). Populasi yang digunakan dalam penelitian ini memiliki beberapa kriteria sebagai berikut: 1) merupakan siswa SMP 1 Kertek, 2) Berjenis 
kelamin laki-laki, dan 3) Aktif dalam kegiatan ekstrakulikuler. Metodologi analisis data menggunakan metode analisis statistik karena data yang diperoleh selama proses penelitian disajikan dengan bentuk numerik atau angka.

\section{Hasil dan Pembahasan}

Dalam setiap melakukan teknik dasar dalam bola voli tentu hampir semua membutuhkan unsur kekuatan. Memukul bola pada saat service membutuhkan kekuatan, mendorong bola saat passing atas membutuhkan kekuatan, smash dibutuhkan kekuatan dan kecepatan (power) tambahan pada saat tumbukan dengan bola, dengan kata lain dalam permainan bola voli menampilkan teknik yang berinteraksi dengan aspek biomotor adalah kekuatan. Berdasarkan pada landasan teori, kinerja service atas dalam cabor bola voli dibagi menjadi tiga aspek utama gerak, yaitu: (1) gerak awalan, (2) gerak ketika memukul, dan (3) gerakan lanjutan. Secara ringkas, berikut rincian detail pelaksanaan service atas dalam permainan: hubungan kekuatan otot lengan dengan keterampilan service bola voli, sehingga servis bola voli dapat mencapai efek yang diharapkan, yaitu melakukan pukulan berkalikali sepanjang pertandingan dan bola diharapkan melaju dengan cepat dan keras sehingga kumpulan otot-otot lengan sangat dibutuhkan ketika melakukan gerakan tersebut. Pukulan servis yang dapat mengarah sampai ke garis belakang wilayah lawan dipengaruhi oleh kekuatan otot yang cukup. Proses pelaksanaan pengambilan data dilakukan pada hari Sabtu, 31 Juli 2021 pukul 08.00 - selesai, yang bertempat di lapangan bola voli SMP 1 Kertek Kabupaten Wonosobo. Deskripsi data pengukuran kekuatan otot lengan pada siswa ekstrakulikuler bola voli di SMP 1 Kertek menunjukkan rata-rata 18,50, nilai SD (standar deviasi) 5,138, nilai kekuatan otot lengan tertinggi 31 poin, dan nilai terendah 12 poin.

Tabel 1. Deskripsi Data Kekuatan Otot Lengan

\begin{tabular}{|c|c|c|c|c|c|c|}
\hline Variabel & & Rata2 & $\begin{array}{l}\text { Standar } \\
\text { Deviasi }\end{array}$ & Rentang & Skor tertinggi & Skor terendah \\
\hline $\begin{array}{l}\text { Kekuatan } \\
\text { Lengan }\end{array}$ & Otot & 18.50 & 5.138 & 19 & 31 & 12 \\
\hline
\end{tabular}

Deskripsi data pengukuran panjang lengan siswa SMP 1 Kertek yang mengikuti ekstrakulikuler bola voli menghasilkan nilai rata-rata sebesar 70,38 dengan nilai SD (standar deviasi) 2,029; skor tertinggi panjang lengan sebesai 74 dan skor terendah 65.

Tabel 2. Deskripsi Data Panjang Lengan

\begin{tabular}{llllll} 
Variabel & Rata2 & $\begin{array}{l}\text { Sstandar } \\
\text { Devisasi }\end{array}$ & Rentang & Skor tertinggi & Skor terendah \\
\hline Panjang Lengan & 70,38 & 2,029 & 9 & 74 & 65
\end{tabular}


Deskripsi data pengukuran panjang lengan siswa SMP 1 Kertek yang mengikuti ekstrakulikuler bola voli menghasilkan nilai rata-rata sebesar 17,06; nilai SD (standar deviasi) 4,057; skor tertinggi tes servis atas sebesar 24 dan skor terendah sebesar 11.

Tabel 3. Deskripsi Data Tes Servis Atas

\begin{tabular}{llllll} 
Variabel & Rata2 & $\begin{array}{l}\text { Standar } \\
\text { Deviasi }\end{array}$ & Range & Skor tertinggi & Skor terendah \\
\hline Hasil Servis Atas & 17.06 & 4.057 & 13 & 24 & 11
\end{tabular}

Berdasarkan hasil dari uji normalitas, dapat disimpulkan bahwa data penelitian yang meliputi kekuatan otot lengan, panjang lengan, dan hasil servis siswa ekstrakulikuler bola voli SMP 1 Kertek dalam keadaan normal, sehingga dapat dilanjutkan ke uji linieritas. Untuk mengetahui hubungan masing-masing variabel bebas dengan variabel terikat bersifat linier digunakan uji linieritas. Berdasarkan hasil perhitungan yang dibantu dengan aplikasi SPSS versi 20 diperoleh nilai $\mathrm{F}_{\text {hitung }} 0,937<\mathrm{F}_{\text {tabel }} 4,49$. Karena nilai dari $\mathrm{F}_{\text {hitung }}$ lebih kecil dari $\mathrm{F}_{\text {tabel}}$, maka hubungan antara variabel kekuatan otot lengan $\left(\mathrm{X}_{1}\right)$ dengan hasil servis atas $(\mathrm{Y})$ bersifat linier. Penghitungan linieritas pada variabel $\mathrm{Y}$ (Hasil Servis Atas) dan variabel $\mathrm{X}_{2}$ (Panjang Lengan) diperoleh nilai $\mathrm{F}_{\text {hitung }} 2,240<\mathrm{F}_{\text {tabel }} 4,49$. Dikarenakan nilai dari $\mathrm{F}_{\text {hitung }}$ lebih kecil dari $\mathrm{F}_{\text {tabel}}$, maka hubungan antara variabel panjang lengan (X2) dengan variabel hasil servis atas (Y) bersifat linier. Dari hasil perhitungan data tersebut maka diketahui bahwa ada hubungan yang bersifat linier antara masing-masing variabel bebas dengan variabel terikat. Kemudian dari hasil uji linieritas dapat dilanjutkan dengan uji hipotesis.

Hasil uji hipotesis pertama menjelaskan bahwa "ada hubungan antara kekuatan otot lengan siswa luar bola voli SMP 1 Kertek dengan skor servisnya". Dari hasil analisis dapat diketahui nilai korelasi (r) sebesar 0,769 dan tingkat probabilitas $0,000<0,05$ yang dijelaskan oleh persamaan regresi $\mathrm{Y}=5,827+0,607 \mathrm{X} 1$. Kekuatan otot lengan merupakan bagian tubuh yang sangat penting, agar servis bola voli dapat diselesaikan dengan baik dan benar. Hasil pengujian hipotesis yang kedua dapat dijelaskan bahwa "ada hubungan panjang lengan dengan hasil servis atas pada siswa ekstrakulikuler bola voli SMP 1 Kertek". Nilai korelasi yang diperoleh dari hasil anaisis adalah (r) 0,548 dengan tingkat probabilitas 0,028 < $\alpha$ 0,05 yang dijelaskan melalui persamaan regresi nilai $\hat{Y}=-60,008+1,095 \mathrm{X}_{2}$. Dari hasil diatas menunjukkan bahwa servis atas bola voli dapat dilakukan dengan baik karena adanya peran penting dari panjang lengan yang merupakan komponen fisik. Hasil pengujian hipotesis ketiga dikemukakan bahwa "ada hubungan kekuatan otot lengan dan panjang lengan dengan hasil servis atas pada siswa ekstrakulikuler bola voli SMP 1 Kertek". Hal ini bisa diketahui dari hasil analisis dimana diperoleh nilai korelasi (r) 0,858 dengan tingkat probabilitas $0,000<\alpha 0,05$ yang dijelaskan melalui persamaan regresi nilai $\hat{Y}=-47,929+$ $0,536 X_{1}+0,783 X_{2}$. Dengan hasil yang diperoleh ini, maka hasil menunjukkan bahwa kekuatan otot lengan dan panjang lengan merupakan unsur fisik yang penting untuk hasil servis atas bola voli baik.

Tabel 4. Interpretasi koefisien korelasi 


\begin{tabular}{cc} 
Interval koefisien & Tingkat hubungan \\
\hline $0,00-0,199$ & Sangat Rendah \\
$0,20-0,399$ & Rendah \\
$0,40-0,599$ & Sedang \\
$0,60-0,799$ & Tinggi \\
$0,80-1,000$ & Sangat Tinggi
\end{tabular}

Dari tabel diatas dapat dilihat seberapa tinggi tingkat hubungan antara kekuatan otot lengan dengan nilai $r$ sebesar 0,769 pada tingkat hubungan hubungan yang tinggi. Dari tabel diatas dapat diketahui seberapa besar hubungan antara kekuatan otot lengan dengan hasil servis atas bola voli yang memiliki nilai $\mathrm{r}$ 0,769 adalah berada pada tingkat hubungan yang tinggi. Tingkat hubungan antara panjang lengan dengan hasil servis atas dengan nilai $\mathrm{r}=$ 0,548 berada pada tingkat hunbungan yang sedang. Kemudian tingkat hubungan antara kekuatan otot lengan dan panjang lengan dengan hasil servis atas dengan nilai $r=0,858$ adalah pada tingkat yang sangat tinggi. Kunci agar servis atas dalam permaian bola voli dapat berhasil dilakukan adalah kekuatan otot lengan, pukulan bola menjadi keras dan kuat dikarenakan adanya daya dorong dari gerakan lanjutan lengan. Siswa yang memiliki kekuatan otot yang besar dapat dipastikan dapat melakukan servis atas bola voli yang baik, sebaliknya apabila kekuatan otot lengan yang tidak baik maka hasil servis atasnya pun akan jelek. Pengaruh positif yang diberikan kekuatan otot lengan yang baik terhadap pukulan yang menggunakan daya. Bisa melakukan pukulan bola yang sempurna merupakan keuntungan ketika mempunyai daya yang besar. Berdasarkan hasil analisis ada hubungan yang tinggi antara kekuatan otot lengan dengan hasil servis atas pada siswa ekstrakulikuler bola voli SMP 1 Kertek.

Dalam melakukan keterampilan gerak servis atas membutuhkan peran panjang lengan. Hal tersebut dikarenakan bahwa dalam melakukan gerakan service atas dalam bola voli membutuhkan gerakan ayunan lengan yang berpangkal pada pangkal lengan yang memberikan kekuatan pukulan pada saat perkenaan dengan bola. Servis atas dapat dilakukan siswa dengan baik apabila siswa memiliki gerakan lengan yang baik dan mantap. Dampak positif dari gerakan lengan yang panjang dan teratur yang berkaitan dengan penggunaan panjang tuas pada saat melakukan suatu pukulan. Tuas lengan yang lebih panjang akan lebih memberikan keuntungan ketika melakukan pukulan terhadap bola. Berdasarkan hasil analisis, ada hubungan yang sedang antara panjang lengan dengan hasil servis atas pada siswa ekstrakulikuler bola voli SMP 1 Kertek. Berdasarkan hasil dari penelitian yang telah dilakukan terdapat hubungan hasil servis atas bola voli dengan kekuatan otot lengan dan panjang lengan. Hal ini disebabkan karena untuk melakukan servis atas dibutuhkan kekuatan otot lengan dan panjang lengan sebagai faktor keberhasilannya. Apabila kekuatan otot lengan sebagai alat gerak untuk memukul tidak kuat dan memiliki lengan dengan kondisi yang pendek maka, hasil pukulan terhadap bola tidak akan maksimal dan kemungkinan besar bola akan tersangkut pada net. Berdasarkan hasil analisis, ada hubungan yang sangat tinggi antara kekuatan otot lengan dan panjang lengan secara bersama-sama dengan hasil servis atas pada siswa ekstrakulikuler bola voli di SMP 1 Kertek.

\section{Kesimpulan}

Berdasarkan analisis data, pengujian hipotesis, dan pembahasan yang telah diperoleh, dapat disimpulkan bahwa: (1) Ada hubungan yang tinggi antara kekuatan otot lengan dengan hasil servis atas pada siswa SMP 1 Kertek yang mengikuti ekstrakulikuler bola voli, (2) Ada 
hubungan yang sedang antara panjang lenga dengan hasil servis atas pada siswa SMP 1 Kertek yang mengikuti ekstrakulikuler bola voli, dan (3) Ada hubungan secara bersama-sama yang sangat tinggi antara kekuatan otot lengan dan panjang lengan dengan hasil servis atas pada siswa SMP 1 Kertek yang mengikuti ekstrakulikuler bola voli. Guru pendidikan jasmani dan olahraga diharapkan dapat selalu mencari dan menambah wawasan yang lebih luas lagi mengenai cabang olahraga permainan bola voli, khususnya pada materi servis atas. Dan diharapkan guru pendidikan jasmani dan olahraga mampu menguasai materi baik teori maupun mempraktikan dan lebih meningkatkan kualitas sebagai seorang pendidik.

\section{Daftar Pustaka}

Ahmadi, N. (2007). Panduan Olahraga BolaVoli. Era Pustaka Utama.

Alimin. (2019). Pengaruh Power Lengan, Panjang Lengan, Dan Koordinasi Mata Tangan Terhadap Keterampilan Passing Bawah Dalam Permainan Bola Voli Pada Siswa SMK Negeri 10 Makassar.

Azmi, M. N. (2017). Hubungan Antara Kekuatan Otot Lengan, Power Otot Lengan Dan Panjang Lengan Dengan Hasil Ketepatan Service Atas Bolavoli Siswa Putra Ekstrakurikuler SMK Queen Al Falah Ploso Mojo Kediri Tahun Ajaran 2017/2018.

Bagia, I. M. (2020). Korelasi Panjang Lengan dan Kekuatan Otot Lengan terhadap Jauhnya Lemparan Cakram Gaya Menyamping di SMP Ganesha Denpasar. Jurnal Pendidikan Kesehatan Rekreasi, 6(1), 108-118.

Bachdar, A. Z. J. (2020). HUBUNGAN KEKUATAN OTOT LENGAN DAN PANJANG LENGAN SERTA KELENTUKAN TOGOK DENGAN KEMAMPUAN PUKULAN SERVIS LOB DALAM PERMAINAN BULUTANGKIS PADA SISWA MTs NURUT TAQWA MANADO. Journal of Islamic Education: The Teacher of Civilization, 2.

Effendi, A. R. (2015). Hubungan Latihan Kekuatan Otot Lengan Dan Panjang Lengan Terhadap Kemampuan Servis Atas Permainan Bola Voli. Journal of Chemical Information and Modeling, 53(9), 1689-1699.

Effendi, A. R. (2016). Hubungan Latihan Kekuatan Otot Lengan Dan Panjang Lengan Terhadap Kemampuan Service Atas Permainan Bola Voli. Jurnal Pendidikan Olah Raga, 4(1), 44-55.

Faizin, A., \& Hariadi, I. (2019). Hubungan Antara Panjang Lengan dan Kekuatan Otot Lengan terhadap Lemparan Kedalam pada Siswa. Indonesia Performance Journal, 3(2), 101-107.

Istyadi, A. R. I. (2007). Hubungan Kekuatan Otot Lengan Dan Panjang Lengan Dengan Hasil Servis Atas Bola Voli Pada Siswa Putera Ekstrakurikuler Ma Darul Ma'arif Pringapus Kab. Semarang Tahun Pelajaran 2006/2007. Skripsi Universitas Negeri Semarang.

Istyadi, A. (2007). Hubungan Kekuatan Otot Lengan dan Panjang Lengan dengan Hasil Servis Atas Bola Voli pada Siswa Putera Ekstrakurikuler MA Darul Ma'arif Pringapus Kab. Semarang Tahun Pelajaran 2006/2007 (Doctoral dissertation, Universitas Negeri Semarang).

MA'ARIF, S. Y. A. M. S. U. L., \& REKREASI, D. HUBUNGAN KEKUATAN OTOT LENGAN DAN PANJANG LENGAN DENGAN HASIL SERVIS BAWAH BOLA VOLI PADA SISWA PUTRA EKSTRAKURIKULER MTs. NU NURRAHMAT SIDOMULYO DUKUN GRESIK TAHUN PELAJARAN 2015/2016.

Nurhasan. (2000). Tes dan Pengukuran Pendidikan Olahraga. FPOK UPI: Bandung.

Oktaria, R., Sinurat, R., \& Janiarli, M. (2020). HUBUNGAN KEKUATAN OTOT LENGAN DAN PANJANG LENGAN DENGAN KEMAMPUAN LEMPAR CAKRAM 
SISWA KELAS XI IPS 1 SMA N 1 RAMBAH. Journal Of Sport Education and Training, 1(1), 1-8.

Permendiknas No 22 Tahun 2006. (2006). Pedoman pengembangan diri. Kementrian Pendidikan Nasional.

Pratama, B. A. (2020). HUBUNGAN KEKUATAN OTOT LENGAN, PANJANG LENGAN DAN KOORDINASI MATA TANGAN DENGAN KETEPATAN SMASH PADA ATLET VOLI PUTRI KLUB PERVIK KOTA KEDIRI.

Ruskin, R., \& Liputo, N. (2021). Hubungan Panjang Lengan Dan Kekuatan Otot Lengan Dengan Kecepatan Pukulan Gyaku TsukI. Jambura Journal of Sports Coaching, 3(2), 60-67.

Ryanto, A. K. Y. (2017). Hubungan Panjang Lengan dan Kekuatan Otot Lengan Terhadap Prestasi Memanah Jarak 18 Meter Ronde Nasional. JUDIKA (JURNAL PENDIDIKAN UNSIKA), 5(1).

Samsudin. (2011). Pembelajaran Pendidikan Jasmani Olahraga dan Kesehatan SD. Litera.

Sistiasih, V. S., Nurhidayat, \& Sudarmanto, E. (2019). Permainan Bola Voli. Muhammadiyah University Press.

Sugiyono. (2015). Statistika untuk Penelitian. ALFABETA, cv.

Saputra, S. H., Kusuma, I. J., \& Festiawan, R. (2020). Hubungan tinggi badan, panjang lengan dan daya tahan otot lengan dengan keterampilan bermain bulutangkis. Jurnal Pendidikan Olah Raga, 9(1), 93-108.

Setiyaningsih, P. (2007). HUBUNGAN KEKUATAN OTOT LENGAN DAN PANJANG LENGAN DENGAN HASIL SERVIS BAWAH BOLA VOLI PADA SISWA PUTERA EKSTRAKURIKULER SMP NEGERI 9 SEMARANG TAHUN PELAJARAN 2006/2007 (Doctoral dissertation, Universitas Negeri Semarang).

Susanti, I. D., Husin, S., \& Jubaedi, A. (2018). Hubungan Kekuatan Otot Lengan Dan Panjang Lengan Dengan Kemampuan Servis Atas. JUPE (Jurnal Penjaskesrek), 6(1).

Sukur, A. (2011). HUBUNGAN KEKUATAN OTOT LENGAN DAN PANJANG LENGAN DENGAN HASIL SERVIS ATAS PADA SISWA PUTERI EKSTRAKURIKULER BOLA VOLI SMA $\mathrm{N} 1$ SUBAH KABUPATEN BATANG (Doctoral dissertation, universitas negeri semarang).

Saputro, P. P. (2009). Hubungan kekuatan otot lengan, panjang lengan, terhadap hasil servis bawah bola voli dengan tangan tertutup pada siswa putri SMP Negeri 6 Pekalongan Tahun 2009 (Doctoral dissertation, Universitas Negeri Semarang).

Utama, R. R., \& Asri, A. (2020). Hubungan Kekuatan Otot Lengan dan Panjang Lengan Terhadap Kemampuan Smash dalam Permainan Bola Voli Siswa Kelas XI SMK Negeri 10 Makassar. Sports Review Journal, 1(1), 36-42.

Utama, R. R., \& Asri, A. (2021). HUBUNGAN KEKUATAN OTOT LENGAN DAN PANJANG LENGAN TERHADAP KEMAMPUAN SMASH DALAM PERMAINAN BOLA VOLI SISWA KELAS XI SMK NEGERI 10 MAKASSAR. Journal PJKR, 1(1), 55-63.

Winarsih, U. (2020). Hubungan Kekuatan Otot Lengan, Panjang Lengan dan Koordinasi Mata Tangan Terhadap Kemampuan Servis Atas dalam Permainan Bolavoli Putri pada Klub Vita Solo Usia 13-15 Tahun 2020.

Yundarwati, S., \& Primayanti, I. (2018). Hubungan antara kekuatan otot lengan dan panjang lengan terhadap prestasi lempar cakram pada siswa kelas X SMAN 3 Praya tahun pelajaran 2015/2016. Jurnal Ilmiah Mandala Education, 2(1), 28-32. 